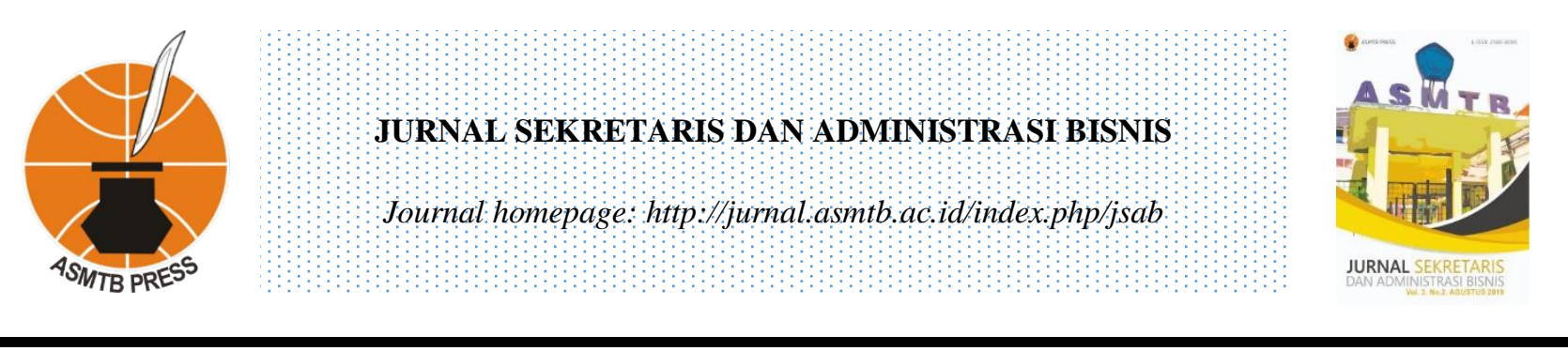

The Influence of Endorser Credibility on Brand Equity 'Shopee for Men' with Self-Brand Connection as a Mediator

\title{
Pengaruh Endorser Credibility terhadap Brand Equity 'Shopee for Men' dengan Self-Brand Connection sebagai Mediator
}

\author{
${ }^{1)}$ Ade Multi Davista Sari, ${ }^{2}$ Citra Kusuma Dewi \\ ${ }^{1,2)}$ Prodi Administrasi Bisnis, Fakultas Komunikasi dan Bisnis, Universitas Telkom \\ ${ }^{1)}$ ademulti@student.telkomuniversity.ac.id, ${ }^{2}$ citrakusumadewi@telkomuniversity.ac.id
}

\begin{tabular}{l} 
Article info \\
\hline Article history: \\
Received 18th April 2019 \\
Received in revised form 15th May 2019 \\
Accepted 20th August 2019
\end{tabular}

\section{Keywords:}

Endorser credibility,

Brand equity,

Self-brand connection,

Shopee, Indonesia

\begin{abstract}
Shopee is one of the markets that provide online trading platforms in Indonesia. Shopee is known by consumers as a brand associated with brands only for women. Though Shopee is a neutral market and is aimed at all circles. Brand equity. This will have an impact on consumer preferences including male consumers of the Shopee brand. Shopee has a strategy by launching the 'Shopee for Men' program and using Bambang Pamungkas and Vincent Rompies as supporters to change consumer perceptions that Shopee is a market for all people and forms Shopee brand equity. The factor that can shape the equity band is the credibility of endorsers and their own brand connections. Therefore the purpose of this study was to determine the effect of endorser credibility on brand equity with self-brand connection as a mediator. This study uses a quantitative method with a type of descriptive causal research. The sampling technique in this study was purposive sampling which is a part of non probability. Respondents from this study were 100 consumers with male sex living on the island of Java. This study uses SEMPLS data analysis techniques. The results of this study are endorser credibility, brand equity and self-brand connections in 'Shopee for Men' in the high category. There is a positive influence between credibility of endorsers and brand equity and self-brand connections have an indirect influence or as a mediator between credibility of endorsers and brand equity.
\end{abstract}




\section{Pendahuluan}

PT Shopee Internasional Indonesia merupakan sebuah perusahaan yang menyediakan platform belanja online di Indonesia. Shopee memiliki tujuan untuk terus berkembang menjadi $e$ commerce pilihan utama di Indonesia. Shopee menawarkan berbagai macam kebutuhan pengguna secara netral (allgender) untuk pria dan wanita seperti pakaian, alat rumah tangga, alat elektronik hingga pembayaran listrik dan lain-lain. Shopee menawarkan produk yang sedang trend dipasar dengan harga terjangkau, kualitas serta pelayanan terbaik.

Shopee dikenal oleh konsumen sebagai brand yang di asosiasikan dengan brand hanya untuk kalangan perempuan. Padahal Shopee merupakan marketplace yang netral dan ditujukan semua kalangan bukan untuk kalangan perempuan. Sehingga dapat disimpulkan bahwa Shopee memiliki isu terkait brand equity karena brand Shopee dipersepsikan hanya untuk kalangan perempuan. Hal ini akan berdampak kepada preferensi konsumen termasuk konsumen pria terhadap brand Shopee.

Dengan adanya masalah terkait brand equity tersebut maka Shopee mengatasinya dengan dua strategi. Strategi pertama adalah dengan meluncurkan program 'Shopee for Men' dan yang kedua adalah dengan menggunakan Bambang Pamungkas dan Vincent Rompies sebagai endorser. Dengan kedua strategi tersebut diharapkan mampu mengubah persepsi konsumen dimana Shopee merupakan marketplace netral untuk semua kalangan bukan hanya untuk perempuan serta membentuk brand equity Shopee. Adapun faktor yang membentuk brand equity adalah endorser credibility dan selfbrand connection.

Endorser yang dipilih merupakan selebritas yang memiliki kredibilitas dari segi attractiveness, trustworthiness, dan expertise. Dengan berbagai daya tarik yang dimiliki oleh Bambang Pamungkas dan Vincent Rompies, keahlian dengan produk yang didukung serta kepercayaan akan mempengaruhi persepsi konsumen, dimana hal tersebut secara teori dinamakan Endorser Credibility (Dwivedi, 2015). Dari berbagai hal yang telah dikemukakan sebelumnya dapat disimpulkan bahwa strategi Shopee dengan menggunakan selebriti endorser yang memiliki kredibilitas yang baik dan juga menggunakan fitur 'Shopee for Men' akan mempengaruhi self-brand connection sehingga ada keterikatan antara konsumen Shopee terutama laki-laki dengan Shopee. Dari hal tersebut Shopee berharap akan terbentuk suatu ikatan yang kuat dan berarti antara merek dengan para konsumen yang secara teori dinamakan Self-Brand Connection (Dwivedi, 2015). Adapun dari ikatan tersebut dapat menambah nilai yang ditambahkan oleh sebuah merek ke dalam sebuah produknya yang secara teori disebut Brand Equity (Mirabi, 2016). 


\section{Kerangka Teori}

\section{Endorser Credibility}

Kredibilitas endorser merupakan kemampuan seorang tokoh atau publik figur yang dikenal oleh masyarakat yang digunakan sebagai media untuk menyampaikan suatu pesan kepada konsumen yang nantinya penyampaian pesan tersebut diharapkan dapat menimbulkan niat membeli (Hansudoh dalam Mahadewi, 2014). Tiga dimensi yang membentuk kredibilitas selebriti menurut Dwivedi (2015) yaitu :

1. Attractiveness

Mengacu pada persepsi konsumen dari daya tarik fisik seorang endorser. Indikator pembentuk daya tarik yaitu penampilan yang baik, menarik serta penampilan yang memikat (Palentina, 2017; Dwivedi, 2015; Stephanie, 2013; Spry, 2011).

\section{Trustworthiness}

Mengacu pada kejujuran, integritas, dan tingkat kepercayaan yang terkait dengan seorang endorser. Indikator dari kepercayaan yaitu seorang endoser harus terpercaya, jujur, dan dapat diandalkan (Palentina, 2017; Dwivedi, 2015; Stephanie, 2013; Spry, 2011).

\section{Expertise}

Keahlian adalah persepsi konsumen tentang pengetahuan, pengalaman atau kemampuan seorang pendukung dengan produk yang didukung. Indikator dari keahlian yaitu ketika endorser sesuai kualifikasi, berpengetahuan, seorang ahli, memiliki pengalaman yang baik serta terampil (Palentina, 2017; Dwivedi, 2015; Stephanie, 2013; Spry, 2011).

\section{Brand Equity}

Kotler \& Amstrong, 2016 mendefinisikan ekuitas merek sebagai efek diferensial yang mengetahui nama merek terhadap ukuran kemampuan merek untuk menangkap preferensi dan loyalitas konsumen. Sedangkan mnurut Kotler \& Keller, 2013 ekuitas merek adalah nilai tambah yang diberikan pada produk dan jasa. Adapun dimensi dari brand equity menurut Aaker yang diadaptasi oleh Mirabi (2016) yaitu:

\section{Brand Awareness}

Brand awareness adalah citra atau kekuatan merek yang hadir dalam materi abu-abu konsumen. Kesadaran merek terdiri dari brand recall dan brand recognition. Indikator dari brand awareness yaitu mengenali, mengetahui, serta beberapa karakteristik brand muncul dengan cepat dibenak konsumen (Shabbir, 2017; Mirabi, 2016; Dwivedi, 2015; Wowor, 2014; Spry, 2011). 


\section{Brand Association}

Brand association adalah berbagai arti seputar merek. Indikator dari brand association adalah kepercayaan, suka serta kebanggaan terhadap suatu brand (Shabbir, 2017; Mirabi, 2016; Dwivedi, 2015; Wowor, 2014; Spry, 2011).

\section{Perceived Quality}

Perceived Quality adalah terkait bagaimana konsumen mengevaluasi merek. Adapun indikator dari perceived quality yaitu kualitas yang sangat tinggi, kualitas yang sangat konsisten, dapat diandalkan, serta menawarkan yang terbaik (Shabbir, 2017; Mirabi, 2016; Dwivedi, 2015; Wowor, 2014; Spry, 2011).

\section{Brand Loyalty}

Brand Loyalty adalah kecenderungan untuk setia pada merek fokal yang dibuktikan dengan niat untuk membeli merek tersebut sebagai pilihan utama. Indikator dari brand loyalty adalah setia dan brand menjadi pilihan pertama (Shabbir, 2017; Mirabi, 2016; Dwivedi, 2015; Wowor, 2014; Spry, 2011).

\section{Self-Brand Connection}

Menurut Dviwedi (2015) Self-Brand Connection merupakan hubungan merek diri sebagai pembentukan ikatan yang kuat dan bermakna antara merek tertentu dan identitas diri konsumen. Adapun indikator dari self-brand connection yaitu mengategorikan brand dengan konsumen, brand membantu konsumen menjadi seseorang yang dia inginkan, konsumen merasa ada koneksi personal dengan brand, konsumen dapat menggunakan brand untuk mengomunikasikan mengenai dirinya ke orang lain, brand mencerminkan diri konsumen yang sesungguhnya, konsumen dapat mengidentifikasi dirinya dengan brand.

\section{Framework}

Berdasarkan beberapa rumusan masalah dan literatur yang ditampilkan sebelumnya, maka dirumuskanlah kerangka pemikiran sebagai berikut:

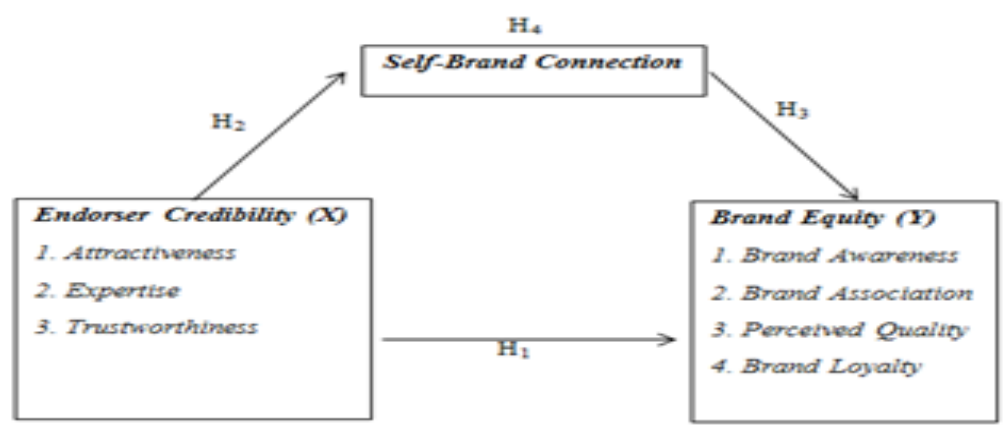

Gambar 1. Kerangka Pemikiran

Sumber: diadaptasi dari Dwivedi (2015) 
Hipotesis 1: Endorser Credibility berpengaruh positif terhadap Brand Equity pada Shopee

Hipotesis 2: Endorser Credibility berpengaruh positif terhadap Self-Brand Connection pada Shopee

Hipotesis 3: Self-Brand Connection bepengaruh positif terhadap Brand Equity pada Shopee

Hipotesis 4: Self-Brand Connection berpengaruh sebagai mediator antara Endorser Credibility dengan Brand Equity

\section{Metode Penelitian}

Penelitian ini menggunakan metode kuantitatif dengan jenis penelitian kausal deskriptif. Teknik sampling pada penelitian ini adalah purposive sampling yang merupakan bagian dari nonprobability. Responden dari penelitian ini merupakan konsumen Shopee dengan jenis kelamin lakilaki yang tinggal di pulau Jawa sebanyak 100 responden. Penelitian ini menggunakan teknik analisis data SEM-PLS.

\section{Hasil dan Diskusi}

\section{Uji Validitas}

Berdasarkan dari hasil uji validitas yang telah dilakukan, dari 31 butir pernyataan dalam kuisioner yang disebarkan kepada 30 responden memiliki nilai korelasi (rhitung) diatas 0,361 (rtabel) sehingga semua pernyataan valid dan layak digunakan dalam analisis regresi linier sederhana.

\section{Uji Reliabilitas}

Nilai Cronbach's Alpha dalam penelitian ini adalah 0,882 untuk endorser credibility, 0,935 untuk brand equity dan 0,931 untuk self-brand connection sehingga dapat disimpulkan semua kuesioner dalam penelitian ini reliabel atau konsisten karena nilai cronbach's alpha $>0,60$.

\section{Analisis Deskriptif}

a) Variabel Endorser Credibility

Tabel 1 Tanggapan Responden Mengenai Variabel Endorser Credibility

\begin{tabular}{|c|c|c|c|}
\hline No. Item & Dimensi & Skor & Rata-rata Presentase \\
\hline $1,2,3$ & Attractiveness & 1100 & $73,3 \%$ \\
\hline $4,5,6,7,8$ & Trustworthiness & 1892 & $75,68 \%$ \\
\hline $9,10,11,12,13$ & Expertise & 1836 & $73,44 \%$ \\
\hline \multicolumn{3}{|c|}{ Jumlah Skor } & 4828 \\
\hline \multicolumn{3}{|c|}{ Presentase } & $74,14 \%$ \\
\hline
\end{tabular}


Berdasarkan hasil perhitungan menunjukkan bahwa nilai yang diperoleh adalah 4.828 atau sebesar $74,14 \%$. Dengan demikian dapat dilihat bahwa Endorser Credibility dalam program 'Shopee for Men' di PT Shopee Internasional Indonesia yang terdiri attractiveness, trustworthiness, dan expertise termasuk dalam kategori baik dimana PT Shopee Internasional Indonesia tepat memilih Bambang Pamungkas dan Vincent Rompies sebagai endorser 'Shopee for Men'.

b) Variabel Brand Equity

Tabel 2 Tanggapan Responden Mengenai Variabel Brand Equity

\begin{tabular}{|l|l|c|l|}
\hline \multicolumn{1}{|c|}{ No. Item } & \multicolumn{1}{|c|}{ Dimensi } & \multicolumn{1}{c|}{ Skor } & Rata-rata Presentase \\
\hline $14,15,16$ & Brand Awareness & 1089 & $72,6 \%$ \\
\hline $17,18,19$ & Brand Association & 1094 & $72,9 \%$ \\
\hline $20,21,22,23$ & Perceived Quality & 1484 & $74,2 \%$ \\
\hline 24,25 & Brand Loyalty & 684 & $68,4 \%$ \\
\hline \multicolumn{2}{|r|}{ Jumlah Skor } & 4351 \\
\hline \multicolumn{2}{|r|}{ Presentase } & $72,51 \%$ \\
\hline
\end{tabular}

Sumber: Hasil olahan peneliti (2018)

Berdasarkan hasil perhitungan menunjukkan bahwa nilai yang diperoleh adalah 4351 atau sebesar 72,51\%. Dengan demikian dapat dilihat bahwa Brand Equity dalam program 'Shopee for Men' di PT Shopee Internasional Indonesia yang terdiri brand awareness, brand association, perceived quality dan brand loyalty termasuk dalam kategori baik dimana PT Shopee Internasional Indonesia memiliki ekuitas merek yang baik.

c) Variabel Self-Brand Connection

Tabel 3 Tanggapan Responden Mengenai Variabel Self-Brand Connection

\begin{tabular}{|c|l|l|l|}
\hline No. Item & Dimensi & Skor & Rata-rata Presentase \\
\hline $26,27,28,29,30,31$ & Self-brand connection & 2089 & $69,6 \%$ \\
\hline \multicolumn{2}{|c|}{ Jumlah Skor } & 2089 \\
\hline \multicolumn{2}{|c|}{ Presentase } & $69,6 \%$ \\
\hline
\end{tabular}

Sumber: Hasil olahan peneliti (2018)

Berdasarkan hasil perhitungan menunjukkan bahwa nilai yang diperoleh adalah 2089 atau sebesar 69,63\%. Dengan demikian dapat dilihat bahwa self-brand connection dalam program 'Shopee for Men' di PT Shopee Internasional Indonesia termasuk dalam kategori baik. 
Analisis Path Coefficient

Tabel 4 Hasil Uji Direct Effect

\begin{tabular}{|c|c|c|c|c|c|}
\hline & $\begin{array}{c}\text { Standard. } \\
\text { beta }\end{array}$ & $\begin{array}{c}\text { Standard } \\
\text { error }\end{array}$ & T statistics & P values & Simpulan \\
\hline $\begin{array}{c}\text { Endorser Credibility -> } \\
\text { Brand Equity }\end{array}$ & 0,277 & 0,073 & 3,808 & 0,000 & supported \\
\hline $\begin{array}{c}\text { Endorser Credibility -> Self- } \\
\text { brand connection }\end{array}$ & 0,663 & 0,072 & 9,253 & 0,000 & supported \\
\hline $\begin{array}{c}\text { Self-brand connection -> } \\
\text { Brand Equity }\end{array}$ & 0,683 & 0,067 & 10,236 & 0,000 & supported \\
\hline
\end{tabular}

Sumber: Hasil olahan SmartPLS (2018)

Berdasarkan tabel 3 dapat dilihat bahwa keseluruhan hipotesis memiliki $\mathrm{p}$ value $<0,05$ dan $\mathrm{t}$ statistics $>1,65$ sehingga keseluruhan hipotesis dinyatakan memiliki pengaruh postif.

\section{Analisis Mediator Effect}

Tabel 5 Hasil Uji Mediator Effect

\begin{tabular}{|c|c|c|c|c|c|}
\hline & $\begin{array}{c}\text { Standard } \\
\text { Beta }\end{array}$ & $\begin{array}{c}\text { Standard } \\
\text { Error }\end{array}$ & $\begin{array}{c}\text { T } \\
\text { statistics }\end{array}$ & P value & Simpulan \\
\hline $\begin{array}{c}\text { Endorser Credibility -> Self-brand } \\
\text { Connection > Brand Equity }\end{array}$ & 0,452 & 0,059 & 7,644 & 0,000 & supported \\
\hline
\end{tabular}

Sumber: Hasil olahan SmartPLS (2018)

Berdasarkan tabel 5 dapat disimpulkan bahwa terdapat pengaruh tidak langsung sebesar $45,2 \%$ antara variabel endorser credibility terhadap brand equity dengan self-brand connection sebagai mediator.

\section{Simpulan}

Berdasarkan hasil penelitian dan pembahasan yang telah dikemukakan sebelumnya dapat diambil beberapa simpulan sebagai berikut pertama, endorser credibility (x) pada 'Shopee for Men' secara keseluruhan termasuk ke dalam kategori baik atau tinggi. Dalam endorser credibility yang memiliki nilai terendah ialah dimensi attractiveness atau daya tarik. Kedua, brand equity (y) pada 'Shopee for Men' secara keseluruhan termasuk ke dalam kategori baik atau tinggi. Dalam brand equity yang memiliki nilai terendah ialah brand loyalty. Ketiga, self-brand connection (z) pada 'Shopee for Men' secara keseluruhan termasuk ke dalam kategori baik atau tinggi. Dalam self-brand 
connection yang memiliki nilai terendah adalah 'Shopee for Men' mencerminkan diri saya yang sesungguhnya. Keempat, terdapat pengaruh positif antara endorser credibility terhadap brand equity. Kelima, terdapat pengaruh positif antara endorser credibility terhadap self-brand connection. Keenam, terdapat pengaruh positif antara self-brand connection terhadap brand equity. Terakhir, Selfbrand connection memiliki pengaruh tidak langsung antara variabel endorser credibility terhadap brand equity.

\section{Arah Penelitian di Masa Depan}

Penelitian ini hanya meneliti tentang pengaruh endorser credibility terhadap brand equity dengan self-brand connection sebagai mediator pada program 'Shopee For Men' di PT Shopee Internasional Indonesia, maka untuk penelitian selanjutnya disarankan melanjutkan penelitian Dwivedi (2015), dengan menganalisa variabel lain yang terkait dengan brand equity misalnya advertising. Selain itu, melakukan penelitian dengan variabel yang sama namun dilakukan pada objek yang berbeda. 


\section{Referensi}

Dwivedi, A., Johnson, L. W., \& McDonald, E. R. (2015). Celebrity endorsement, self-brand connection and consumer-based brand equity. Journal of Product \& Brand Management, 449461.

Dwivedi, A., Johnson, L. W., \& McDonald, R. (2015). Celebrity endorsement, self-brand connection and relationship quality. International Journal of Advertising, 1-18.

Kotler, P., \& Amstrong, G. (2016). Principles Of Marketing. England: Pearson Limited Education.

Kotler, P., \& Keller, K. L. (2013). Marketing Management. England: Pearson Education Limited.

Mirabi, V. R., \& Lajevardi, M. (2016). A conceptual Model in Marketing: Celebrity Endorsement, Brand Credibility and Brand Equity. Journal of Marketing and Consumer Research, 38-43.

Palentina, P. (2017). Pengaruh Celebrity Endorser's Credibility terhadap Self-Brand Connection. Jurnal Bisnis Dan Akuntansi, 271-284.

Shabbir, M. Q., Khan, A. A., \& Khan, S. R. (2017). Brand Loyalty Brand Image And Brand Equity: The Mediating Role Of Brand. International Journal of Innovation and Applied Studies, 416423.

Spry, A. (2011). Celebrity endorsement, brand credibility and brand equity. European Journal of Marketing, 882-900.

Spry, A. (2011). Celebrity endorsement, brand credibility and brand equity. European Journal of Marketing, 882-900.

Triwijanarko, R. (2018, Agustus 1). Upaya Shopee Move On dari Cap e-Commerce Khusus Perempuan. Retrieved Agustus 8, 2018, from Marketeers: http://marketeers.com/shopeemencoba-move-on/

Widyajayanti, N. M., \& Kusuma, A. A. (2017). Peran Self-Brand Connection Dalam Memediasi Pengaruh Kredibilitas Endorser Terhadap Brand Equity Para Brand Guess. E-Jurnal Manajemen Unud, 3342-3369.

Wowor, S., \& Lunarjanto, A. (2014). Pengaruh Brand Equity dan Pricing Terhadap Purchase Intention Maskapai Low Cost Carrier di Jakarta. Journal of Business Strategy and Execution, 45-81. 